\title{
Imaging techniques as a method of sectional examination in forensic veterinary medicine
}

\author{
MAŁGORZATA GRELA, PIOTR LISTOS, MAGDALENA GRYZIŃSKA*, \\ WOJCIECH CHAGOWSKI**, GRZEGORZ BUSZEWICZ**, GRZEGORZ TERESIŃSKI**
}

\author{
Department and Clinic of Animal Internal Diseases, Sub-Department of Pathomorphology and Forensic Medicine, \\ Faculty of Veterinary Medicine, University of Life Sciences, Głęboka 30, 20-612 Lublin, Poland \\ *Institute of Biological Basis of Animal Production, Faculty of Biology, Animal Sciences and Bioeconomy, \\ University of Life Sciences, Akademicka 13, 20-950 Lublin, Poland \\ **Department of Forensic Medicine, Faculty of Medicine with English Language Division, \\ Medical University of Lublin, Jaczewskiego 8, 20-090 Lublin, Poland
}

Grela M., Listos P., Gryzińska M., Chagowski W., Buszewicz G., Teresiński G. Imaging techniques as a method of sectional examination in forensic veterinary medicine

Summary

An autopsy or necropsy can be performed only once; therefore, its proper execution is of fundamental importance in explaining the cause of death. The protocol with photographic documentation is an integral part of the autopsy, but sometimes it does not fully reflect the state of the body and the pathological changes observed at each stage of the procedure. These shortcomings are addressed by modern imaging techniques, which are increasingly used during the autopsy of human bodies, but quite rarely during necropsy of animals. Non-invasive techniques (CT, MRI, or photogrammetry with laser body scanning), or in some cases also minimally invasive techniques (biopsy), enable comprehensive analysis of the carcass, but Virtopsy is only a supplement to the classical autopsy, especially in veterinary forensic medicine.

Keywords: forensic medicine, computed tomography, magnetic resonance, photogrammetry, laser scanning

An autopsy, referred to in veterinary medicine as a necropsy, consists of an external examination, including determination of the species, breed, gender and age of the animal; a description of pathological and traumatic skin lesions; and an internal examination, by opening the main body cavities and examining the internal organs inside them. The purpose of the necropsy is to establish the cause of death and to identify the accompanying circumstances, which usually determine the type of necropsy to be performed. In veterinary medicine, four categories of necropsy are distinguished: clinical, medico-legal, administrative, and commissioned by individuals or various types of legal entities (businesses).

\section{Legal proof from sectional studies}

A necropsy can be performed only once, and therefore its proper execution is of fundamental importance in explaining the cause of death (22). The protocol with photographic documentation is an integral part of the necropsy, but it does not always fully reflect the state of the body and the pathological changes observed at each stage of the procedure. These shortcomings are addressed by modern imaging techniques, which are increasingly used during autopsy (of human bodies), but quite rarely during necropsy (23).

The recording of changes found during necropsy in the form of images is invaluable in the case of examinations carried out for judicial purposes, as the results of the necropsy can be reproduced at any time during legal proceedings. In addition, radiological techniques are a direct tool in investigating material truth in cases such as traffic accidents (detection of trauma and skeletal changes), shooting (detection of foreign bodies in the body of the victim), or identification of the body (analysis of individual skeletal traits; e.g. congenital or post-traumatic lesions). Radiology was first used for forensic purposes in 1896, just after the publication in the Viennese newspaper Die Presse of a report on Roentgen's discovery of a new kind of radiation - X-rays (19). At that time, an X-ray of a leg with a gunshot wound, taken by a physicist (Professor John Cox of McGill University in Montreal), became physical evidence in the case against Georg Holder, 
who was accused of attempted murder (5). The first X-ray examination for Polish forensic medicine was done in 1930 by Tadeusz Rogalski (Jagiellonian University in Krakow), to identify the perpetrator of a fatal shooting (36).

Imaging techniques have greatly evolved since the time of Roentgen, and successive radiological achievements have been implemented on an ongoing basis in forensic practice. A significant advance was the introduction of computer tomography in 1972. In 1989 a modification of this technique, spiral computed tomography, enabled three-dimensional reconstruction (51). A comparative analysis of CT results with the results of a conventional autopsy was the starting point for collaboration begun in 2000 between the Institute of Forensic Medicine and the Radiology Department of the University of Bern. This collaboration resulted in a research project and with it the introduction of a novel technique for examining a carcass: the Virtopsy ${ }^{\circledR}$ (Virtual Autopsy). The Swiss team designed the Virtopsy as an objective, non-invasive method of post-mortem examination, to be used primarily by law enforcement agencies (43). The essence of the virtual autopsy is the analysis of data obtained using techniques such as computed tomography (also CT + angiography and/or biopsy), magnetic resonance imaging, photogrammetry and laser scanning of the surface of the body (6).

\section{Virtopsy in veterinary medicine}

The literature dealing with the application of Virtopsy in veterinary medicine is quite scarce. In most published works, animals have served as model organisms for the purpose of evaluating the suitability of post-mortem imaging methods for veterinary practice and forensic opinions. Kraft et al. (20) emphasized the usefulness of magnetic resonance in pathomorphological assessment of the lungs, based on the example of guinea pigs infected with Mycobacterium tuberculosis. Jackowski (18), using a pig model (ex vivo), and Grabherr et al. (9), using the carcasses of dogs and a cat, carried out computed tomography in combination with angiography. Their results confirm the diagnostic value of this method in the case of damage and pathological lesions within the vascular system. Toklu et al. (44) demonstrated the usefulness of imaging techniques in the diagnosis of drowning in a rat model. Based on post-mortem radiographic examination of the chest and abdomen of dogs and cats, Heng et al. described the time- and ambient temperature-dependent accumulation of putrefaction gases in specific internal organs and vessels of the circulatory system (13-15).

Several studies have compared the results of traditional and virtual necropsy. Cattaneo et al. (3) used piglets to compare the effectiveness of traditional necropsy, radiological analysis (X-rays) and computed tomography in the detection of traumatic bone lesions (3). The results, in the form of the number of identified fractures, were varied for each method and depended on the location of the damage. Hence, the authors stressed the need to apply all of these techniques together for each case. Hostettler et al. (16) analysed the carcasses of 11 Bernese Mountain Dogs with suspected histiocytic sarcoma. Prior to the standard necropsy, computed tomography was performed in conjunction with a biopsy. Although the classic necropsy techniques proved more effective in that case, the authors maintain that improvements in the biopsy protocol and CT scanning will increase the diagnostic value of these methods (16).

In addition to experimental research, post-mortem imaging techniques have found their place in a relatively young branch of veterinary medicine - veterinary forensics. The primary purpose of forensic veterinary medicine is to determine the causes of death of an animal for the needs of judicial bodies. Within this discipline a necropsy is usually performed in the case of sudden death resulting from external factors. The concept of 'external factors' should be understood as incidents such as traffic accidents, deliberate killing, and abuse (22).

The forensic necropsy is carried out by a veterinarian appointed as an expert, whose opinion constitutes evidence for which the judicial body has high expectations regarding the certainty of the diagnosis (38). Hence, extraordinary meticulousness and constant selfeducation are unquestionably required of the individual performing the necropsy. For this reason, modern post-mortem imaging methods have gradually begun to appear among the tools of expert veterinarians. The use of these techniques in veterinary forensics was described in 2007. Thali et al. performed X-rays and computed tomography (3D MSCT) of the carcass of a Eurasian lynx (Lynx lynx) found shot in a plastic bag in front of a Swiss supermarket. The data obtained were used to establish the track of the gunshot wounds and the type of weapon used, and consequently the group of persons suspected of this crime (poaching) was narrowed down. Thalli's team, which normally deals with virtual autopsy of human bodies, strongly emphasized the utility of this method for the purposes of veterinary forensics as well $(39,40,43)$. A virtopsy of a shot animal was also carried out by Franckenberg et al. (7). The carcass of a fox shot by a hunter was subjected to comprehensive analysis using computed tomography (also in combination with angiography) and magnetic resonance imaging (7). The tools revealed lesions resulting from the effect of the bullet in the skeletal system, soft tissues and blood vessels. This made it possible to conclusively establish the cause of death and to resolve doubts circulating among hunters as to whether the ammunition used to kill the game causes sudden death without unnecessary suffering. Morrow et al. (27) used data from CT acquisition to explain the unexpected increase in mortality among caged chickens at an Australian farm, and emphasized the 
usefulness of computed tomography to identify traumatic lesions in birds (27).

\section{Characterization of post-mortem imaging techniques}

Conventional X-rays. Radiography, based on the phenomenon of differentiated absorption of the X-ray beam passing through different tissues of the body, is the oldest post-mortem imaging technique. When Roentgen announced his discovery, he emphasized the potential application of the new radiation not only to locate bullets in patients' bodies, but also in forensic medicine $(29,45)$. Currently X-rays of carcasses are a fixed element of the autopsy protocol. This is an inexpensive and simple technique which is useful for evaluating lesions and damage in the skeletal system (Fig. 1), detecting foreign bodies, or identifying unknown bodies. Radiography is also a basic stage of the most-mortem examination in forensic veterinary practice, and is compulsory in the case of a suspected shooting (24). Detection and localization of bullet fragments (Fig. 2) or various types of sharp objects using $\mathrm{X}$-ray images facilitates the work of the examiners, and also reduces their risk of injury during the necropsy. Radiography is also a screening tool used prior to magnetic resonance imaging to detect potentially ferro-

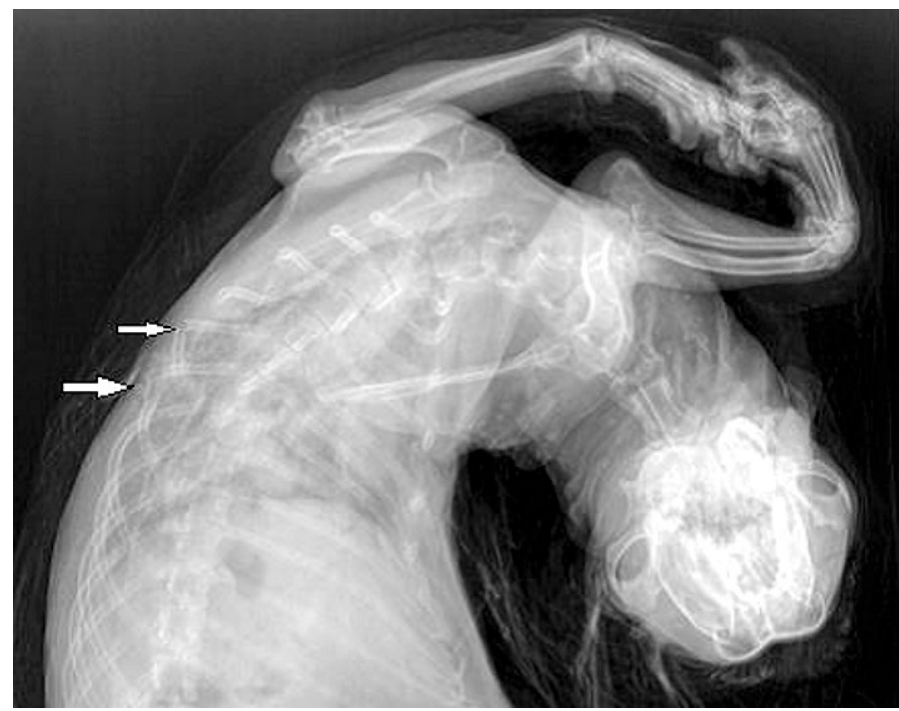

Fig. 1. Radiographic image of gunshot injuries to bone tissue - rib fracture in a dog (arrows)
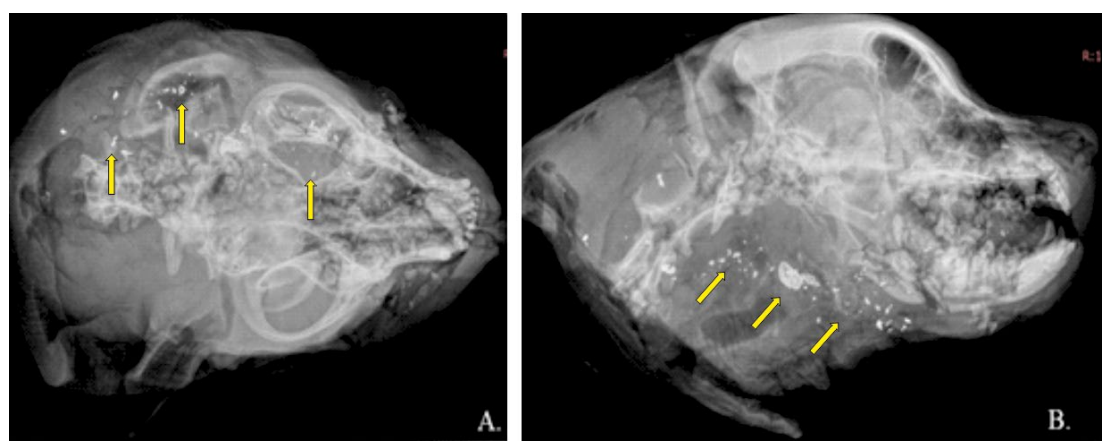

Fig. 2. Radiographic image of gunshot injuries to a dog's head: numerous bullet fragments visible (arrows). A - dorsoventral view, B - laterolateral view magnetic metals present in the body, a contraindication for this type of test. Although modern radiology offers many other, more accurate techniques, $\mathrm{X}$-rays are still included among post-mortem imaging methods, as evidenced by the literature $(11,13,14,24,33)$.

Computed tomography (CT). Computed tomography is another imaging technique that uses X-radiation. However, there are differences in how the examination is performed and how the results are presented. The object under examination is repeatedly scanned with an X-ray beam using a generator rotating around it, while an array of detector elements continuously records the measurement values corresponding to the linear absorption coefficients of the radiation. These data form the basis for the second stage of CT: reconstruction of the image (51). Since the first scan performed using the EMI prototype scanner (1971), the CT imaging technique has evolved considerably. Currently available CT scanners can be used to create not only 2D images but 3D images as well, which is of tremendous significance for the forensic sciences. Owing to the option of presenting the data in spatial form, or even a dynamic presentation, a CT scan of the skeleton makes it possible to determine the mechanism by which the injuries occurred. This technique is accurate enough to enable the identification of minor traumas such as fractures of the transverse processes of the vertebrae, which is difficult in a conventional autopsy. Another problem solved by computed tomography is the detection of very small foreign bodies in the carcass, such as glass shards, which weakly absorb $\mathrm{X}$-rays (45). A significant advantage of CT over conventional radiography is the ability to determine the spatial localization of a foreign body and visualize the course of the channel it has made (Fig. 3), which is often of fundamental importance for reconstruction of the event $(45,48)$. Owing to its high contrast resolution, CT is used for imaging of parenchymal organs and soft tissues. This allows for the identification of pathological changes such as cerebral haemorrhages, pneumoperitoneum, cardiac rupture, and aortic rupture (45). The important role of CT is underscored in the case of the examination of bodies found in water, where analysis of the lungs, airways and sinuses makes it easier to determine the cause of death by drowning (49).

The use of computed tomography as a tool for post-mortem imaging is still rare in necropsies as compared to autopsies of human bodies, due to the high cost of the technique and the limited availability of equipment. It should also be noted that in veterinary medicine, the CT apparatus must be adjusted to the varied sizes of animals (17). Yamada et al. (50) drew attention to the problem of animal size, conducting post-mortem imaging of the carcass of a month-old foal (50). 

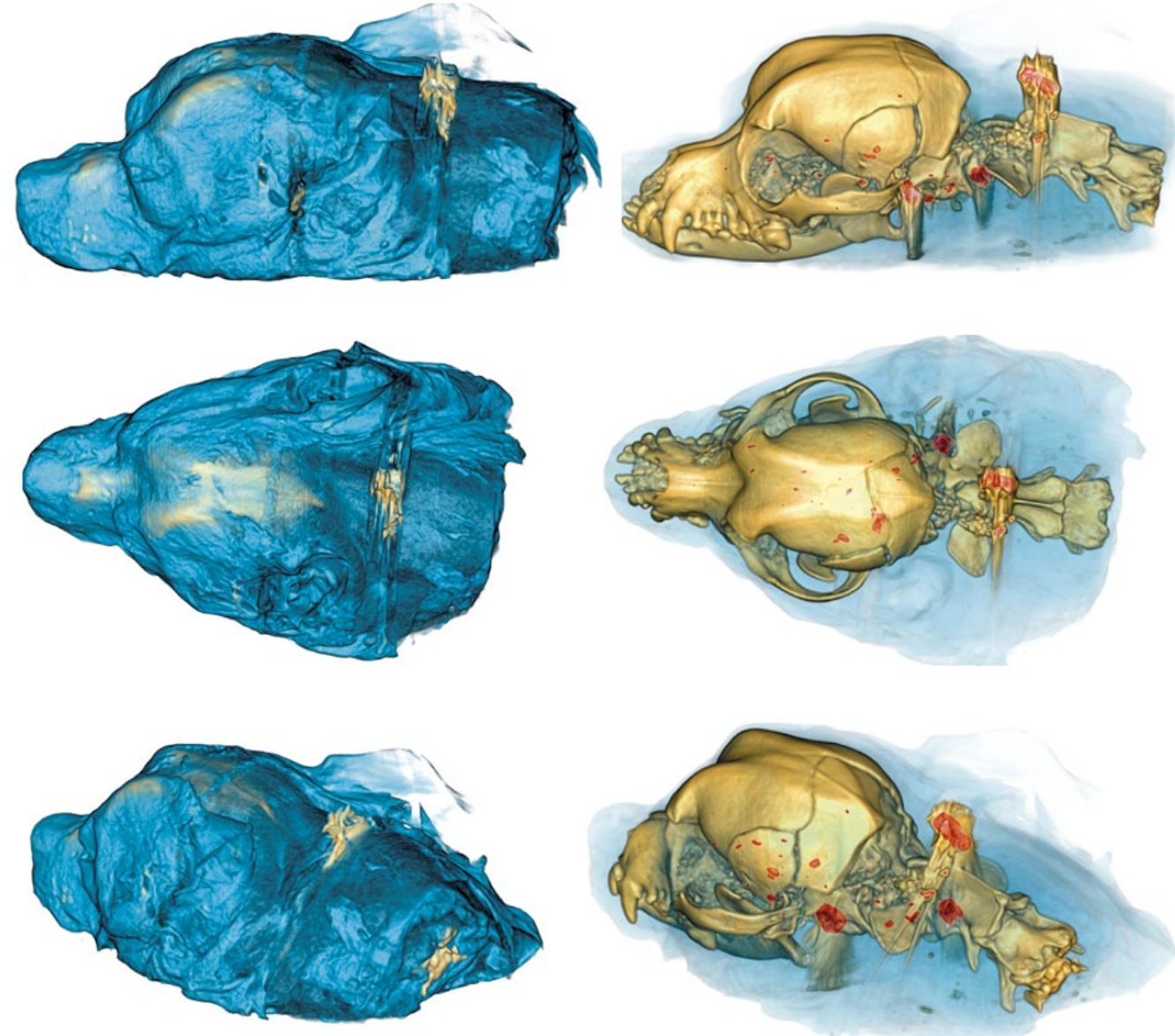

Fig. 3. CT scan of head of a dog shot with a shotgun. Bullet fragments visible in the form of red elements

CT with angiography and/or fine needle aspiration. The possibilities of post-mortem CT are even greater when combined with other techniques. One such combination, CT angiography (PMCTA - post mortem computed tomography angiography), enables the visualization of pathological changes within the vascular system, which cannot be achieved by the standard CT protocol. Initially, two-step post-mortem angiography was used, with paraffin oil as a contrast agent and an external pump responsible for its distribution, resembling a heart-lung machine for cardiac surgery. CT acquisition was performed during operation of the pump. Currently, a multi-phase procedure is commonly used - multi-phase post mortem computed tomography angiography (MPCT), which includes a native $\mathrm{CT}$ scan prior to administration of the contrast agent, followed by contrast imaging in three angiographic phases: arterial, venous and dynamic (artificial circulation) (8). Comparing the data obtained in this manner with the results of medico-legal autopsies of 50 corpses, Chevallier et al. (4) reported an increase in the diagnostic value of MPMCTA as compared to native CT from $65 \%$ to $80.9 \%$, while conventional autopsies identified $83.1 \%$ of pathological lesions. Post-mortem CT angiography is indicated in the case of deaths attributable to surgical interventions (52), cardiovascular disease (26) and various types of trauma, where it is important to assess damage to anatomical structures and to determine the source of haemorrhage $(28,30)$. CT angiography is especially useful in analysing small vascular lesions in locations that are difficult to access $(26,28,30,52)$. Because PMCTA is a relatively young technique that has not yet been perfected, the data it collects are still compared to the results of autopsy and histopathological examinations, during which changes caused by the contrast agent, and especially the paraffin distributing it, should be taken into account. The use of contrast also necessitates prior collection of material (blood, urine or bile) for toxicological tests (28).

Besides angiography, another technique combined with CT is fine-needle aspiration biopsy. This is a minimally invasive diagnostic method that allows for quick and accurate collection of material for histopathological examination. CT-guided biopsy is performed when the native CT images show small focal lesions within organs, such as cancer lesions, and histopathological evaluation is needed for a definitive diagnosis. Sometimes post-mortem CT-guided biopsy is used to determine 'injury vitality', for example by identifying a fat embolism in the lungs, which occurs in motor vehicle accidents (25). Another application of this method is the collection of body fluids for toxicological and/or microbiological tests (1). A great advantage of this technique is that it eliminates the risk of contaminating the sample of biological material. Furthermore, it is easy to perform because in the case of carcasses we are not dealing with a patient's uncontrolled movements, and the time of exposure to radiation does not play a role (25).

Magnetic resonance imaging (MRI). The introduction of magnetic resonance imaging was a huge step forward in the development of radiological diagnostics, extending the possibilities of thanatological radiology by enabling detailed imaging of soft tissue lesions. The MR technique is based on the phenomenon of nuclear magnetic resonance, which exploits the effect of the excitation of hydrogen protons and their relaxation. The part of the body being examined is placed in a strong magnetic field. A radio signal with the appro- 
priate resonance frequency is sent through a transmitter, resulting in the excitation of hydrogen protons. When the signal is turned off and the protons return to their original state, radio waves are emitted and picked up by a receiver. The signal can be described by a formula in which there are two constants: T1 and T2 (called relaxation times). Particular types of tissues, depending on the concentration of hydrogen atoms, which are primarily present in molecules of water $\left(\mathrm{H}_{2} \mathrm{O}\right)$ and fat $\left(\mathrm{CH}_{2}\right)$, have characteristic relaxation times. The visible effect of this is different shades of grey in different parts of the image of the body part, resulting from processing of the signal by computer software. MR imaging can be performed in several different sequences, providing different data with varied diagnostic possibilities. For example, a T1 image best represents the anatomical structure of the brain (white matter appears in light colours and grey matter in dark colours). Cerebrospinal fluid, an abscess or a tumour will be dark. In the imaging of a motor organ, adipose tissue will be clear, while structures with high water content and without fat will be dark (cartilage, menisci, and ligaments), and muscles will be grey. In contrast, in T2 imaging of the brain, white matter appears in darker shades and grey matter in lighter ones. Cerebrospinal fluid, an abscess or a tumour will be light in this sequence. In the imaging of a motor organ, adipose tissue will be grey and synovial fluid or a haematoma will be light $(37,47)$. In a STIR (short time inversion recovery) sequence, the adipose tissue signal is eliminated, enabling detection of infection, bone marrow oedema, muscle oedema or tumours, as well as of fluids accumulating in pathological spaces, which is especially important in medico-legal autopsies $(35,37,47)$. PMMR is therefore a precise diagnostic tool, primarily used to evaluate the abdominal organs, brain, heart and subcutaneous fat. Nevertheless, the technique is considered to be most useful in the analysis of the vascular system, as unlike autopsy and histopathological examination, MR can be used to detect the early stage of myocardial ischaemia (35).

However, achieving a high quality image in postmortem MR visualization can be problematic due the dependence of the $\mathrm{T} 1$ and $\mathrm{T} 2$ relaxation times on temperature. The changes in temperature that take place when the body cools have been shown to affect the quality of the image. During T2 imaging the contrast between adipose tissue and muscle tissue was found to decrease at temperatures below $20^{\circ} \mathrm{C}$, while in the $\mathrm{T} 1$ sequence the deterioration of image quality accompanying the decrease in temperature was observed below $10^{\circ} \mathrm{C}(34)$. Other factors that affect the quality of post-mortem MR images include the degree of decomposition of the body and the hypostasis which occurs immediately after circulation stops. Interpretation of PMMR results, due to the need to distinguish images of naturally occurring post-mortem changes (such as position-dependent sedimentation or post-mortem clot- ting) from pathological changes, is not an easy task, and therefore an experienced radiologist plays a key role in determining the cause of death using MR (35). Due to the limited availability of this type of specialist and especially of MR equipment, the high cost of purchasing and operating it, and the long examination time, MR is used only sporadically in post-mortem examination of both human and animal carcasses.

Photogrammetry and laser scanning of the surface of the body. The imaging techniques presented above unquestionably improve the quality and effectiveness of post-mortem examinations performed by pathologists. In the past, however, a significant limitation of these techniques was the inability to analyse body integuments and the fact that images could only be generated in shades of grey, so that the external examination of the body was based solely on the knowledge and experience of the pathologist (31). These restrictions were eliminated by introducing photogrammetry, routinely used by the police to reconstruct road accidents. This technique involves the creation of spatial models from two-dimensional photographs. Photogrammetry is combined with laser scanning of the surface of the body (3D/CADsupported photogrammetry), making it possible to produce spatial documentation of injuries to the body, with information of previously unattainable quality: a 3D image in colour (40). The creators of Virtopsy ${ }^{\circledR}$ used the TRITOP/ATOS II laser system for analysis of external injuries to the body, where TRITOP is the photogrammetric component and ATOS is a scanning system. Using the same combination of techniques, the Swiss team also scanned objects which had been the cause of particular injuries. By comparing 3D models of the objects with models of the injuries (the morphologic fingerprint), the use of these objects could be confirmed or ruled out. Similarly, cases have been analysed in which the skin was damaged by a bite or by the victim being run over by a mechanical vehicle. Bite marks or tyre tracks on the body of the victim were compared with a model of the suspect's teeth or of a tyre tread pattern. It should be noted that additional data (evidence in the form of 3D models) can be added to the results of the virtual analysis of the skin at any time. For example, a weapon used during an assassination and found several months later is scanned, and the resulting model is compared with the results of a previously performed autopsy. This provides the opportunity for a new analysis of the injuries, supplemented with new data which may be essential to the case (6).

By using special computer software, data obtained through photogrammetry and laser body scanning can be combined with CT or MRI images. This fusion of the results of external and internal examination of a body in virtual space provides not only a comprehensive and precise analysis of the damage to the skin, but also an explanation of the mechanism by which they came about, and thus a reconstruction of the sequence 
of events during various types of accidents and crimes $(6,40)$.

In light of the available literature and our own experience, the use of 3-D/CAD-supported photogrammetry seems particularly justified for analysis of the integuments of animal carcasses, with particular focus on the needs of veterinary forensics.

\section{Advantages and disadvantages of post-mortem imaging (PMI)}

The above description of the techniques on which virtual autopsy is based show the broad spectrum of post-mortem imaging possibilities. Each of these methods has both advantages and certain disadvantages (Tab. 1). Nevertheless, their combined use unquestionably increases the effectiveness of autopsy diagnostics (8).

In considering posthumous imaging as an alternative to conventional autopsies, in addition to purely diag- nostic considerations other significant aspects support their use in forensic thanatology and their implementation in general forensic veterinary practice. The short time required to analyse the entire body (using modern CT equipment), which means that virtopsy can be treated as a routine method for preliminary analysis, enables optimal planning of the classical necropsy and increases the likelihood of identifying all relevant pathological changes $(12,21,41)$. Data obtained from the PMI are recorded in digital form so that the body can be evaluated at any time, regardless of decomposition or cremation; furthermore, the digital record ensures that the results of the virtual necropsy can be repeatedly reproduced and thereby verified, and professionals from around the world can be consulted (known as teleconsulting) (41). In this way, images from the CT/ MRI acquisition supplement medical knowledge and sometimes become a source of it. This is of particular value to veterinarians dealing with a wide variety of

Tab. 1. Advantages, disadvantages and applications of post-mortem imaging in forensic veterinary medicine

\begin{tabular}{|c|c|c|c|}
\hline Technique & Advantages & Disadvantages & Application in veterinary forensics \\
\hline X-ray & $\begin{array}{l}\text { - speed } \\
\text { - easy to perform } \\
\text { - easy to archive data (in the case } \\
\text { of digital radiography) } \\
\text { - low cost }\end{array}$ & $\begin{array}{l}\text { - no reconstruction of 3D images } \\
\text { - limited application - good quality } \\
\text { visualization only for skeletal } \\
\text { system }\end{array}$ & $\begin{array}{l}\text { Identification of pathological lesions in the skeletal } \\
\text { system in cases such as: } \\
\text { - gunshots, } \\
\text { - poaching, } \\
\text { - medical error, } \\
\text { - traffic accidents, } \\
\text { - animal abuse. } \\
\text { Individual identification (chips, prostheses). } \\
\text { Detection of foreign bodies constituting evidence. }\end{array}$ \\
\hline $\begin{array}{l}\text { CT } \\
\text { CT + angiography } \\
\text { CT + biopsy }\end{array}$ & $\begin{array}{l}\text { - fast } \\
\text { - easy to perform } \\
\text { - allows for creation of 3D } \\
\text { reconstructions and dynamic } \\
\text { animations } \\
\text { - minimally invasive } \\
\text { - good quality images of soft tissues } \\
\text { and circulatory system } \\
\text { - minimally invasive } \\
\text { - easy to perform } \\
\text { - low risk of contamination }\end{array}$ & $\begin{array}{l}\text { - data storage (vast amount of data) } \\
\text { - specialists needed to interpret } \\
\text { PMCT images } \\
\text { - relatively time-consuming } \\
\text { - data storage } \\
\text { - need for specialized personnel } \\
\text { - additional costs - contrast agent } \\
\text { - relatively time-consuming } \\
\text { - data storage } \\
\text { - need for specialized personnel }\end{array}$ & $\begin{array}{l}\text { Identification of pathological lesions in cases such } \\
\text { as: } \\
\text { - gunshots, } \\
\text { - poaching, } \\
\text { - medical error (pathological lesions due to } \\
\text { improper treatment), } \\
\text { - traffic accidents, } \\
\text { - animal abuse. } \\
\text { Individual identification. } \\
\text { Detection of foreign bodies constituting evidence. } \\
\text { Any case of suspected vascular damage, need to } \\
\text { determine source of bleeding, e.g.: } \\
\text { - gunshots, } \\
\text { - poaching, } \\
\text { - medical error, } \\
\text { - traffic accidents, } \\
\text { - animal abuse, } \\
\text { - bites, } \\
\text { - collection of body fluids and tissues for diagnostic } \\
\text { tests, e.g. toxicological, microbiological, } \\
\text { histopathological, cytological. }\end{array}$ \\
\hline MRI & $\begin{array}{l}\text { - high-quality visualization of soft } \\
\text { tissues and internal organs }\end{array}$ & $\begin{array}{l}\text { - time-consuming - more difficult } \\
\text { than CT } \\
\text { - need to select appropriate } \\
\text { sequence for 3D reconstruction } \\
\text { - data storage } \\
\text { - need for specialists to interpret } \\
\text { images } \\
\text { - high cost } \\
\text { - limited availability }\end{array}$ & $\begin{array}{l}\text { Identification of pathological lesions in cases such } \\
\text { as: } \\
\text { - gunshots, } \\
\text { - poaching, } \\
\text { - medical error, } \\
\text { - traffic accidents, } \\
\text { - animal abuse, } \\
\text { - suffocation. }\end{array}$ \\
\hline $\begin{array}{l}\text { Photogrammetry + laser } \\
\text { scanning of body surface }\end{array}$ & $\begin{array}{l}\text { - good quality visualization of skin } \\
\text { and objects associated with case } \\
\text { - high resolution } \\
\text { - low cost of operation } \\
\text { - mobility of equipment }\end{array}$ & $\begin{array}{l}\text { - time-consuming } \\
\text { - need for specialists to perform } \\
\text { analyses and process and } \\
\text { interpret data }\end{array}$ & $\begin{array}{l}\text { - reconstruction of traffic accidents } \\
\text { - confirm/rule out objects associated with skin } \\
\text { damage, e.g. animal abuse cases } \\
\text { - confirm/rule out individual suspected of biting } \\
\text { (another animal or person) }\end{array}$ \\
\hline
\end{tabular}


animal species, including endangered species, in which diagnosis is problematic due to the rarity of such cases, with few literature reports describing diseases in these animals (21).

Processing of images from $\mathrm{CT}$ acquisition (postprocessing) allows them to be presented in the form of three-dimensional reconstructions or dynamic animations $(6,39)$, and the clarity and objectivity of PMI images mean that the results of virtopsy are evidence of much better quality than a description or photographs of an autopsy or necropsy. These features, combined with the possibility of creating 3-D reconstructions, reflect the actual state of the pathological lesions in a much simpler manner, which is especially important for people who are not directly involved in forensic medicine, such as judges and lawyers. Also not without significance for everyone involved in the proceedings is the 'bloodlessness' of the evidence from the virtopsy $(6,32)$. Another important advantage is the reduced risk of infection; virtopsy is a non-invasive method which does not involve the use of a scalpel, so that contact with the body is minimal, even if material needs to be taken for microbiological, toxicological or genetic testing. The biological material is then collected in an automated manner, by fine-needle aspiration. This is important for veterinarians who are exposed to zoonotic agents, i.e. animal pathogens with the ability to infect and cause diseases in humans, called zoonoses (e.g. Lyme disease, bovine tuberculosis or avian influenza). In addition, virtopsy provides an image without damaging the body, which is an optimal solution when a classical autopsy cannot be performed for cultural or religious reasons $(6,31,32)$. Similarly, given pet owners' attitude towards companion animals (e.g. dogs and cats), often treating them as family members, we recognize the potential of post-mortem imaging in veterinary medicine.

The possibilities of post-mortem imaging in many respects overcome the barriers of the common autopsy. So can the virtual autopsy completely replace the conventional autopsy? Pathologists agree that the answer is 'no', treating virtopsy as an auxiliary procedure due to certain limitations. The colour, consistency and smell of internal organs are characteristics of high diagnostic value to the experienced pathologist during the examination of the body, and this type of information, except for skin colour in 3D/CAD-supported photogrammetry, is not provided by post-mortem imaging techniques (2). In addition, comparative analysis of virtual and conventional autopsy results indicates that not all pathological lesions, and therefore not all cases of death, can be diagnosed by imaging tests. One example is sudden cardiac death, where ischaemic lesions may not be visible in CT imaging (31). In the case of imaging of the vast majority of the body, and thus analysis of large amounts of data, the likelihood of overlooking minor damage or small pathological lesions increases. Thanatological radiology is a young discipline, espe- cially in the context of veterinary forensics, which means that publications are still scarce and there is a shortage of specialists experienced in interpreting images from post-mortem CT or MRI (2).

Post-mortem imaging has ushered in a new era of forensic thanatology. Integration of non-invasive techniques (CT, MRI, or photogrammetry with laser body scanning) and, in some cases, minimally invasive techniques (fine-needle aspiration), in addition to providing a wide range of possibilities for evaluating the skin and internal structures, simultaneously eliminates problems of a technical (e.g. examination time or risk of infection) and cultural nature. Although virtopsy can be an alternative to the classic autopsy, in most cases it is used to supplement it. This is due to the limitations of post-mortem imaging, described above, and to the fact that it is still fairly new in the forensic sciences. Hence further research is needed, covering a broader spectrum of cases. This applies in particular to veterinary forensics, in which post-mortem imaging techniques are still a novelty.

\section{References}

1. Bolliger S. A., Filograna L., Spendlove D., Thali M. J., Dirnhofer R., Ross S. Postmortem imaging-guided biopsy as an adjuvant to minimally invasive autopsy with CT and postmortem angiography: a feasibility study. Am. J. Roentgenol. 2010, 195, 5, 1051-1056.

2. Bolliger S. A., Thali M. J.: Imaging and virtual autopsy: looking back and forward. Phil. Trans. R. Soc. B 2015, 370, 20140253.

3. Cattaneo C., Marinelli E., Di Giancamillo A., Di Giancamillo M., Travetti O., Vigano'L., Poppa P., Porta D., Gentilomo A., Grandi M.: Sensitivity of autopsy and radiological examination in detecting bone fractures in an animal model: implications for the assessment of fatal child abuse. Forensic Sci. Int. 2006, 164, 131-137.

4. Chevallier C., Doenz F., Vaucher P., Palmiere C., Dominguez A., Binaghi S., et al.: Postmortem computed tomography angiography vs. conventional autopsy: advantages and inconveniences of each method. Int. J. Legal Med. 2013, 127, 981-989.

5. Cox J., Kirkpatrick R. C.: The new photography with report of case in which a bullet was photographed in the leg. Montreal Med. J. 1896, 24, 661.

6.Dirnhofer R., Jackowski C., Vock P., Potter K., Thali, M. J.: VIRTOPSY: Minimally Invasive, Imaging-guided Virtual Autopsy. RadioGraphics 2006, $26,1305-1333$

7. Franckenberg S., Kern F., Vogt M., Thali M. J., Flach P. M.: Fatal gunshot to a fox: The Virtopsy approach in a forensic veterinary case. J. Forensic Radiol. Imaging 2015, 3, 72-75.

8. Grabherr S., Baumann P., Minoiu C., Fahrni S., Mangin P.: Post-mortem imaging in forensic investigations: current utility, limitations, and ongoing development. Res. Rep. Forensic Med. Sci. 2016, 6, 25-37.

9. Grabherr S., Djonov V., Friess A., Thali M. J., Ranner G., Vock P., Dirnhofer R.: Postmortem Angiography After Vascular Perfusion with Diesel Oil and a Lipophilic Contrast Agent. AJR 2006, 187, 515-523.

10. Grabherr S., Grimm J., Dominguez A., Vanhaebost J., Mangin P.: Advances in post-mortem CT-angiography. Br. J. Radiol. 2014, 87.

11. Gumpenberger M., Hochwartner O., Loupal G.: Diagnostic imaging of a renal adenoma in a red oscar (Astronotus ocellatus Cuvier, 1829). Vet. Radiol. Ultrasound 2004, 45, 2, 139-142.

12. Hamano T., Terasawa F., Tachikawa Y., et al.: Squamous cell carcinoma in a Capybara (Hydrochoerus hydochaeris). J. Vet. Med. Sci. 2014, 76, 1301-1304 .

13. Heng H. G., Selvarajah G. T., Lim H. T., Ong J. S., Lim J., Ooi J. T.: Seria postmortem abdominal radiographic findings in canine cadavers. Forensic Sci. Int. 2009, 192, 43-47.

14.Heng H. G., Selvarajah G. T., Lim H. T., Ong J. S., Lim J., Ooi J. T.: Serial postmortem thoracic radiographic findings in canine cadavers. Forensic Sci. Int. 2009, 188, 119-124.

15. Heng H. G., Teoh W. T., Sheikh-Omar A. R.: Postmortem abdominal radiographic findings in feline cadavers. Vet. Radiol. Ultrasound 2008, 49, 26-29. 
16. Hostettler F. C., Wiener D. J., Welle M. M., Posthaus H., Geissbühler U: Post mortem computed tomography and core needle biopsy in comparison to autopsy in eleven bernese mountain dogs with histiocytic sarcoma. BMC Vet. Res. 2015, 11, 229.

17.Ibrahim A. O., Zuki A. B. M., Noordin M. M.: Applicability of Virtopsy in veterinary practice: a short review. Pertanika J. Trop. Agric. Sci. 2012, 35, 1-8.

18. Jackowski C., Sonnenschein M., Thali M. J., Aghayev E., von Allmen G., Yen K., Dirnhofer R., Vock P.: Virtopsy: postmortem minimally invasive angiography using cross section techniques-implementation and preliminary results. J. Forensic Sci. 2005, 50, 1175-1186.

19. Karger B.: Morphological findings in the brain after experimental gunshots using radiology, pathology and histology. Int. J. Legal Med. 1998, 111, 314-319.

20. Kraft S. L., Dailey D., Kovach M., Stasiak K. L., Bennett J., McFarland C. T., McMurray D. N., Izzo A. A., Orme I. M., Basaraba R. J.: Magnetic resonance imaging of pulmonary lesions in guinea pigs infected with Mycobacterium tuberculosis. Infect. Immun. 2004, 72, 10, 5963-5971.

21. Lee K. J., Sasaki M., Miyauchi A., et al.: Virtopsy in a Red Kangaroo with oral osteomyelitis. J. Zoo. Wildl. Med. 2011, 42, 128-130.

22. Listos P., Gryzinska M., Batkowska J.: Postmortem decrease in temperature in the orbit of dogs for use in determining time of death. Slov. Vet. Res. 2016, 53, 85-90.

23. Listos P., Gryzinska M., Kowalczyk M.: Analysis of cases of forensic veterinary opinions produced in a research and teaching unit. J. Forensic Leg. Med. 2015, $36,84-89$.

24. Listos P., Komsta R., Łopuszyński W., Gryzińska M., Teresiński G., Chagowski W., Buszewicz G., Dylewska M.: Radiological and forensic veterinary analysis of gunshot cases in eastern Poland. Med. Weter. 2016, 72, 453-457.

25. Martinez R. M., Ptacek W., Schweitzer W., Kronreif G., F€urst M., Thali M. J., Ebert L. C.: CT-Guided, Minimally Invasive, Postmortem Needle Biopsy Using the B-Rob II Needle-Positioning Robot. J. Forensic Sci. 2014, 59, 2, 517-521.

26. Michaud K., Grabherr S., Doenz F., Mangin P.: Evaluation of postmortem MDCT and MDCT-angiography for the investigation of sudden cardiac death related to atherosclerotic coronary artery disease. Int. J. Cardiovasc. Imaging 2012, 28, 1807-1822.

27. Morrow C. J., Noormohammadi A. H., O'Donnell C. J.: Fatal skull trauma in caged layer chickens associated with a moving feed hopper: diagnosisbased on autopsy examination, forensic computed tomography and farm visit. Avian Pathol. 2012, 41, 391-394.

28. Moskała A., Woźniak K., Kluza P., Bolechała F., Rzepecka-Woźniak E., Kołodziej J., Latacz K. : Przydatność pośmiertnego badania tomografii komputerowej z angiografia (PMCTA) w sądowo-lekarskiej diagnostyce przypadków ran kłutych i ciętych. Arch. Med. Sąd. Kryminol. 2012, LXII, 315-326.

29. Nozdryn-Płotnicki Z., Listos P., Łopuszyński W., Dębiak P.: Section investigation of animals wounded from fire arms: some remarks. Med. Weter. 2005, 61, 887-889.

30. Palmiere C., Binaghi S., Doenz F., Bize P., Chevallier C., Mangin P., et al.: Detection of hemorrhage source: the diagnostic value of post-mortem CTangiography. Forensic Sci. Int. 2012, 222, 33-39.

31. Patowary A. J.: Virtopsy: One Step Forward In The Field Of Forensic Medicine - A Review. J. Indian Acad. Forensic Med. 2008, 30, 1, 32-36.

32. Persson A., Lindblom M., Jackowski C.: A state-of-the-art pipeline for postmortem $\mathrm{CT}$ and MRI visualization: from data acquisition to interactive image interpretation at autopsy. Acta Radiol. 2011, 1, 52, 522-536.

33. Ribas L. M., Massad M. R. R., Tremori T. M., Reis S. T. J., Eising T., et al: Postmortem Analysis of Injuries by Roadkill of a White-eared Opossum (Didelphis Albiventis) by Radiographs and Forensic Necropsy-A Virtopsy Case Report. J. Veterinar. Sci. Technol. 2016, 7.

34. Ruder T. D., Hatch G. M., Siegenthaler L., Ampanozi G., Mathier S., Thali $M . J$. , Weber O. M.: The influence of body temperature on image contrast in post mortem MRI. Eur. J. Radiol. 2012, 81, 1366-1370.

35. Ruder T. D., Thali M. J., Hatch G. M.: Essentials of forensic post-mortem MR imaging in adults. Br. J. Radiol. 2014, 87, 1036.

36. Ryglicki S.: Przyczynek do zastosowania promieni Roentgena w medycynie sądowej. Czas. Sąd. Lek. 1930, 4, 244

37. Siedlecki T., Kowalski H.: Rezonans magnetyczny, [w:] Pruszyński B. (red.) Radiologia - diagnostyka obrazowa, Rtg, TK, USG, MR i radioizotopy. Wydawnictwo PZWL, Warszawa 2001, p. 28-43.

38. Szarek J.: Lekarz weterynarii jako biegły. Wydawnictwo UWM, Olsztyn 2006 , p. 6.

39. Thali M. J., Braun M., Buck U., Aghayev E., Jackowski C., Vock P., Sonnenschein M., Dirnhofer R.: VIRTOPSY - scientific documentation, reconstruction and animation in forensic: individual and real $3 \mathrm{D}$ data based geometric approach including optical body/object surface and radiological CT/MRI scanning. J. Forensic Sci. 2005, 50, 428-442.
40. Thali M. J., Braun M., Wirth J., Vock P., Dirnhofer R.: 3D Surface and Body Documentation in Forensic Medicine: 3-D/CAD Photogrammetry Merged with 3D Radiological Scanning. Forensic Sci. 2003, 48, 1-10.

41. Thali M. J., Jackowski C., Oesterhelweg L., Ross S. G., Dirnhofer R.: VIRTOPSY - The Swiss virtual autopsy approach. Legal Med. 2007, 9, 100 $-104$.

42. Thali M. J., Kneubuehl B. P., Bolliger S. A., Christe A., Koenigsdorfer U., Ozdoba $C$., Spielvogel E., Dirnhofer $R$.: Forensic veterinary radiology: Ballistic-radiological 3D computertomographic reconstruction of an illegal lynx shooting in Switzerland. Forensic Sci. Int. 2007, 171, 63-66.

43. Thali M. J., Yen K., Schweitzer W., Vock P., Boesch C., Ozdoba C., Schroth G., Ith M., Sonnenschein M., Doernhoefer T., Scheurer E., Plattner T., Dirnhofer R.: Virtopsy, a New Imaging Horizon in Forensic Pathology: Virtual Autopsy by Postmortem Multislice Computed Tomography (MSCT) and Magnetic Resonance Imaging (MRI) - a Feasibility Study. Forensic Sci. 2003, 48, 2 , $1-18$.

44. Toklu A. S., Alkan N., Gürel A., Cimsit M., Haktanır D., Körpınar S., Purisa S. Comparison of pulmonary autopsy findings of the rats drowned at surface and $50 \mathrm{ft}$ depth. Forensic Sci. Int. 2006, 164, 122-125.

45. UrbanikA., Chrzan R.: Zastosowanie badania tomografii komputerowej (TK) dla potrzeb medycyny sądowej. Przegląd Lekarski 2013, 70, 229-241.

46. Watson E., Heng H. G.: Forensic Radiology And Imaging For Veterinary Radiologists. Vet. Radiol. Ultrasound 2017, 58, 245-258.

47. Wolny T., Linek P.: Wprowadzenie do diagnostyki obrazowej narządu ruchu dla fizjoterapeutów. Rehabilitacja w praktyce 2016, 1.

48. Woźniak K., Moskała A., Urbanik A., Kłys M.: Pośmiertne badania obrazowe TK $\mathrm{z}$ rekonstrukcją 3D u ofiar postrzałów z broni palnej i eksplozji ładunków wybuchowych. Arch. Med. Sąd. Krym. 2009, LIX, 85-92.

49. Woźniak K., Urbanik A., Rzepecka-Woźniak E., Moskała A., Kłys M.: Pośmiertne badanie obrazowe TK w przypadku domniemanego utonięcia opis przypadku. Arch. Med. Są. Krym. 2009, LIX, 330-336.

50. Yamada K., Sato F., Horiuchi N., Higuchi T., Kobayashi Y., Sasaki N., Nambo Y: Autopsy imaging for cardiac tamponade in a Thoroughbred foal. J. Equine Sci. Vol. 2016, 27, 115-118

51.Zajgner J.: Rentgenodiagnostyka, [w:] Pruszyński B. (red.): Radiologia diagnostyka obrazowa, Rtg, TK, USG, MR i radioizotopy. Wydawnictwo PZWL, Warszawa 2001, p. 43-53.

52.Zerlauth J. B., Doenz F., Dominguez A., Palmiere C., Usk'e A., Meuli R., et al.: Surgical interventions with fatal outcome: utility of multi-phase postmortem CT angiography. Forensic Sci. Int. 2013, 225, 32-41.

Corresponding author: Piotr Listos DVM, PhD, ul. Głęboka 30, 20-612 Lublin; e-mail: piotr.listos@up.lublin.pl 